\title{
Acute respiratory infection and malnutrition among children below 5 years of age in Erbil governorate, Iraq
}

D.A.K. Chalabi

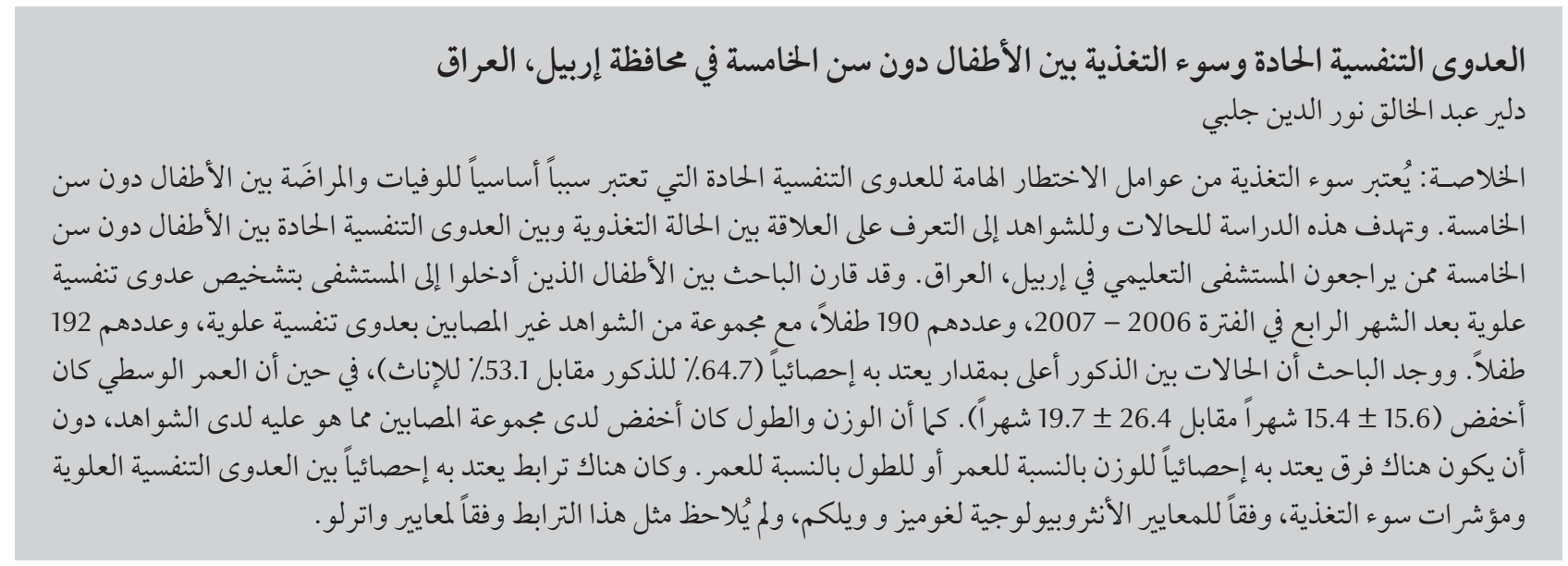

ABSTRACT Malnutrition is an important risk factor for acute respiratory infection (ARI), which is a leading cause of mortality and morbidity among children aged $<5$ years. This case-control study aimed to determine the relationship between nutritional status and ARI among young children aged $<5$ years attending a teaching hospital in Erbil, Iraq. Children admitted to hospital with a diagnosis of ARI over a 4-month period in 2006-2007 $(n=190)$ were compared with a control group without ARI $(n=192)$. Significantly more ARI cases were male (64.7\% versus 53.1\%) and the mean age was lower [15.6 (SD 15.4) versus 26.4 (SD 19.7) months]. Weight and height were lower in the ARI group but there was no significant difference in weight-for-age or in height-for-age. There was a significant association between ARI and indicators of malnutrition according to the Gomez and Welcome anthropometric criteria but not the Waterlow criteria.

Infection respiratoire aiguë et malnutrition chez des enfants de moins de cinq ans dans le gouvernorat d'Erbil (Iraq)

RÉSUMÉ La malnutrition est un facteur de risque important d'infection respiratoire aiguë ainsi qu'une cause majeure de mortalité et de morbidité chez les enfants de moins de cinq ans. La présente étude cas-témoins visait à déterminer la relation entre l'état nutritionnel et l'infection respiratoire aiguë chez des enfants âgés de moins de cinq ans admis à l'hôpital universitaire d'Erbil (Iraq). Les enfants hospitalisés ayant reçu le diagnostic d'infection respiratoire aiguë au cours d'une période de quatre mois en 2006 et $2007(n=190)$ ont été comparés à un groupe témoin sans infection respiratoire aiguë $(n=192)$. Les enfants de sexe masculin étaient nettement plus nombreux à être atteints d'une infection respiratoire aiguë $(64,7 \%$ contre $53,1 \%)$ et l'âge moyen était inférieur $(15,6$ mois [ET 15,4] contre 26,4 mois [ET 19,7]). Le poids et la taille étaient inférieurs dans le groupe des patients infectés mais aucune différence significative n'a été observée pour le poids selon l'âge ou la taille selon l'âge. Il existait une forte association entre une infection respiratoire aiguë et les indicateurs de malnutrition selon les classifications anthropométriques de Gomez et Welcome, mais pas selon les critères de Waterlow. 


\section{Introduction}

Acute respiratory infections (ARI) are major causes of morbidity and mortality in the children of developing countries. While the incidences of ARI are similar in developed and developing countries the course of the disease and the outcomes of ARI may be more severe in developing nations [1]. The effect of poor nutrition, lack of immunization, overcrowding, air pollution and other factors have been reported by several investigators [1,2]. ARI is the cause of almost one-third of all deaths in children $<5$ years of age. Most of these deaths are from pneumonia [2].

Risk factors for deaths in children with ARI have been identified as age $<1$ year, malnutrition and pneumonia as a complication of infection with measles, pertussis, malaria or HIV [3]. Significant associations have also been observed regarding type of feeding and ARI; breastfeeding appears to be highly protective against the occurrence of ARI in infants [4]. The epidemiological evidence is now overwhelming that, even in developed countries, breastfeeding protects against gastrointestinal and to a lesser extent respiratory infection [5]. Malnourished children with severe acute upper respiratory tract infection (URTI) were shown to have a 2-3 times higher mortality rate than healthy children [6]. Malnutrition generally implies undernutrition. In children, undernutrition manifests as underweight and stunting (short stature) while severely undernourished children present with symptoms and signs characteristic of conditions known as kwashiorkor, marasmus or marasmic kwashiorkor [6].

In northern Iraq (including Erbil city) a significant improvement was found between 1994 and 2002 in children's nutritional status; the percentage of underweight children aged $<5$ years fell from $25.8 \%$ in 1994 to $10.7 \%$ in 2002. Nevertheless, among children aged $<5$ years, $13.2 \%$ were underweight in 2000 with $4.3 \%$ acute (wasted) and
$13.0 \%$ chronic (stunted) [7]. The objective of the current study was to study the relationship between nutritional status and ARI among young children attending a teaching hospital in Erbil, Iraq

\section{Methods}

A case-control study was undertaken in Raparin teaching hospital, which is the only specialized paediatric hospital in Erbil city.

\section{Study sample}

A total of 190 children $<5$ years old who were admitted to Raparin hospital with a diagnosis of ARI over a period of 4 months from 1 November 2006 to 1 March 2007 were recruited. The inclusion criteria were all children with respiratory infection who had been admitted to the emergency department during the study period. Neonates and children with known chronic respiratory problems (e.g. asthma, cystic fibrosis, congenital respiratory malformations, tuberculosis), prolonged cough more than 3 weeks, congenital heart disease or foreign body inhalation were excluded from the study. A control sample of 192 children was collected from children attending the paediatric surgical or dental department over the same period for simple surgical procedures, excluding any child with acute or chronic medical illness.

ARI was defined as the presence of cough with or without fever for less than 2 weeks. Acute URTI was diagnosed in those with rhinorrhoea, cough with or without fever, sore throat and tonsillar enlargement, pharyngeal congestion or audible stridor [2]. Acute LRTI was diagnosed in those who presented with prodromal symptoms of rhinorrhoea, cough, fever, with wheeze, dyspnoea, chest retractions, scattered rales and features of hyperinflation, consolidation, patchy or interstitial infiltrates on chest radiography [8].

\section{Data collection}

Information was collected from parents via a face-to-face interview. This included the child's age, sex, duration of illness, symptoms, type of feeding and whether exclusively breastfed in the first 4-6 months. Oral consent was taken from the parents of each child enrolled in the study.

A respiratory system examination was done and anthropometric measures were taken. Weight was measured by precision dial scale (Seca Optima). Participants were weighed in light clothing as far as possible and without shoes. The scales were calibrated before use. Height was measured by using the Centers for Diseases Control measuring board. Individuals were measured barefoot and standing erect, with feet together and head against the measuring rod, looking straight ahead, with arms hanging loosely at the sides and palms facing thighs. Length was measured for children below age of 2 years, with the child lying supine with legs fully extended at the hips and knees and feet at right angles to legs [9].

Three classification systems that are commonly used for assessing growth retardation and nutritional status in the community were applied (Gomez, Welcome and Waterlow) [10] (Table 1). Wasting (decreased weight for length or height) is associated with acute malnutrition and is distinguished from stunting (decreased length-forage or height-for-age) seen with chronic malnutrition. This system depends on a standardized normal distribution using Z-scores in which the 5 th percentile is 2 standard units below the mean [10].

\section{Data analysis}

SPSS, version 18.0 was used for analysis. We used the $t$-test to compare means and the chi-squared test for categorical variables to check the relationship between ARI and demographic, anthropometric and nutritional status variables. $P$-values $\leq 0.05$ were considered 


\begin{tabular}{lll}
\hline Table 1 Classifications of malnutrition used in the current study [6] & \\
Classification & Criteria & Class \\
Gomez & Weight below \% median weight-for-age & \\
& $75 \%-90 \%$ & Mild malnutrition \\
& $60 \%-74 \%$ & Moderate malnutrition \\
& $<60 \%$ & Severe malnutrition \\
Waterlow & Z-scores (SD) below median weight-for-height & \\
& $80 \%-90 \%$ & Mild malnutrition \\
& $70 \%-80 \%$ & Moderate malnutrition \\
& $<70 \%$ & Severe malnutrition \\
WHO, wasting & Z-scores (SD) below median weight-for-height & \\
WHO, stunting & $<3$ rd percentile or Z-scores 2 SD below mean & Moderate and severe wasting \\
& Z-scores (SD) below median height-for-age & \\
Welcome & $<3$ rd percentile or Z-scores 2 SD below mean & Moderate and severe stunting \\
& Weight-for-age & \\
$60 \%-80 \%$ & With oedema: kwashiorkor \\
& $<60 \%$ & Without oedema: undernutrition \\
& & With oedema: marasmus-kwashiorkor \\
\hline
\end{tabular}

$W H O=$ World Health Organization; $S D=$ standard deviation.

statistically significant. Odds ratios (OR) were used to estimate the relative risk of ARI for certain variables with 95\% confidence interval (CI).

\section{Results}

Of the 190 patients with ARI 78 had lower respiratory tractinfection (LRTI), 51 had URTI and 61 had mixed URTI and LRTI.

There was a higher proportion of male children in the ARI group than in the control group (64.7\% versus 53.1\%) $(P=0.02)$ (Table 2). The mean age of the ARI group was significantly lower than the control group $[15.6(15.4)$ versus 26.4 (19.7) months] $P<0.001)$.

Although fewer children in the ARI group were exclusively breastfed compared with the control group (34.7\% versus $43.8 \%$ ), type of feeding was not significantly different between the groups $(P=0.20)$ (Table 2). Breastfeeding was not a significant risk factor, even when exclusive breastfeeding was plotted against both mixed and bottle feeding $(\mathrm{OR}=$ 1.46; 95\% CI: $0.96-2.21, P=0.07$ ).
Mean weight was significantly lower in the ARI group than the controls [8.9 (3.6) kg versus $11.7(4.8) \mathrm{kg}](P<$ $0.001)$ and so were mean height $[73.4$ $(14.5) \mathrm{cm}$ versus $83.4(17.7) \mathrm{cm}](P$ $<0.001)$. However, weight-for-age on growth chart $(P=0.104)$ and heightfor-age on growth chart $(P=0.104)$ were not statistically significantly related to ARI.

There was no significant different between the groups using the Waterlow nutritional state assessment $(P=0.06)$, but ARI was more common among children with indicators of malnutrition according to the Welcome $(P=$ $0.007)$ and Gomez criteria $(P<0.001)$ (Table 2). Two ARI cases had oedema but their weight-for-age was normal so they were not considered as marasmic kwashiorkor or kwashiorkor.

When the Gomez malnourished classes (mild, moderate and severe) were combined the risk of ARI was more than 2-fold higher $(\mathrm{OR}=2.30$; 95\% CI: $1.48-3.58)$. Similarly, when the Welcome malnourished classes (60\%-80\% and $<60 \%$ ) were combined the risk of ARI was also nearly twice as high as in the control group $(\mathrm{OR}=1.95$; 95\% CI: $1.15-3.30$ ).

\section{Discussion}

We found that sex was a risk factor for ARI in this study, in agreement with other studies have shown that males were more vulnerable to ARI than were females $[3,4,11,12]$. Our finding of lower mean age in the ARI group also agrees with findings showing that younger children were more likely to have ARI $[3,4]$, with infants being main group affected. Tupasi et al. in Manila found that age $<2$ years significantly increased the risk of having ARI [13] and Kanchi and Kakeri reported that among children aged $<5$ years with ARI in a Bombay hospital, $40.9 \%$ were $<1$ year of age [12]. One study showed that among 800 children studied, 59\% were boys and $56.3 \%$ were infants with mean age 6.5 (SD 5.6) [11].

Feeding pattern (exclusive breastfeeding, bottle feeding or mixed feeding) was not statistically significant in relation to ARI even when plotted in 


\begin{tabular}{|c|c|c|c|c|c|}
\hline \multirow[t]{2}{*}{ Variable } & \multicolumn{2}{|c|}{$\begin{array}{l}\text { ARI group } \\
(n=190)\end{array}$} & \multicolumn{2}{|c|}{$\begin{array}{l}\text { Control group } \\
\quad(n=192)\end{array}$} & $P$-value \\
\hline & \multicolumn{2}{|c|}{ Mean (SD) } & \multicolumn{2}{|c|}{ Mean (SD) } & \\
\hline Age (months) & \multicolumn{2}{|c|}{$15.6(15.4)$} & \multicolumn{2}{|c|}{$26.4(19.7)$} & $<0.001$ \\
\hline Weight (kg) & \multicolumn{2}{|c|}{$8.9(3.4)$} & \multicolumn{2}{|c|}{$11.7(4.8)$} & $<0.001$ \\
\hline \multirow[t]{2}{*}{ Height(length) $(\mathrm{cm})$} & \multicolumn{2}{|c|}{$73.4(14.5)$} & \multicolumn{2}{|c|}{$83.4(17.7)$} & $<0.001$ \\
\hline & No. & $\%$ & No. & $\%$ & \\
\hline \multicolumn{5}{|l|}{ Sex } & 0.021 \\
\hline Male & 123 & 64.7 & 102 & 53.1 & \\
\hline Female & 67 & 35.3 & 90 & 46.9 & \\
\hline \multicolumn{5}{|l|}{ Feeding } & 0.196 \\
\hline Exclusive breastfeeding & 66 & 34.7 & 84 & 43.8 & \\
\hline Bottle feeding & 49 & 25.8 & 42 & 21.9 & \\
\hline Mixed feeding & 75 & 39.5 & 66 & 34.4 & \\
\hline \multicolumn{5}{|l|}{ Weight-for-age on growth chart } & 0.104 \\
\hline Normal & 143 & 75.3 & 161 & 83.9 & \\
\hline$<5$ th percentile & 34 & 17.9 & 21 & 10.9 & \\
\hline$>$ 95th percentile & 13 & 6.8 & 10 & 5.2 & \\
\hline \multicolumn{5}{|l|}{ Height (length)-for-age on growth chart } & 0.104 \\
\hline Normal & 150 & 78.9 & 156 & 81.3 & \\
\hline$<5$ th percentile & 25 & 13.2 & 14 & 7.3 & \\
\hline$>$ 95th percentile & 15 & 7.9 & 22 & 11.5 & \\
\hline \multicolumn{5}{|l|}{ Weight-for-height (length) (Z scores) } & 0.150 \\
\hline 3SD below & 21 & 11.1 & 11 & 5.7 & \\
\hline Normal & 165 & 86.8 & 175 & 91.1 & \\
\hline 3SD above & 4 & 2.1 & 6 & 3.1 & \\
\hline \multicolumn{5}{|l|}{ Welcome classification } & 0.007 \\
\hline Normal & 144 & 75.8 & 165 & 85.9 & \\
\hline $60 \%-80 \%$ & 40 & 21.1 & 27 & 14.1 & \\
\hline$<60 \%$ & 6 & 3.2 & 0 & 0.0 & \\
\hline \multicolumn{5}{|l|}{ Waterlow classification } & 0.062 \\
\hline Normal & 133 & 70.0 & 153 & 79.7 & \\
\hline Mild & 30 & 15.8 & 27 & 14.1 & \\
\hline Moderate & 22 & 11.6 & 10 & 5.2 & \\
\hline Severe & 5 & 2.6 & 2 & 1.0 & \\
\hline \multicolumn{5}{|l|}{ Gomez classification } & مOPO \\
\hline Normal & 110 & 57.9 & 146 & 76.0 & 0.001 \\
\hline Mild & 52 & 27.4 & 36 & 18.8 & \\
\hline Moderate & 24 & 12.6 & 10 & 5.2 & \\
\hline Severe & 4 & 2.1 & 0 & 0.0 & \\
\hline
\end{tabular}

$S D=$ standard deviation

2 categories (exclusive breastfeeding breastfeeding had no clear protective versus other feeding patterns). This in agreement with previous studies in Iraq by Albargish and Hasony [14] and Yousef and Khaleq [4] in which forms of ARI [15], while other studies in other developing countries showed that children under 5 years with ARI were mainly, partially or not breastfed up to 6 months $[11,16]$. Again, Arifeen et al. compared exclusive breastfeeding 
in the first few months of life with partial or no breastfeeding and its effect on ARI as mortality rate increase by 2.23 fold in those with no exclusive breastfeeding [17].

Children with lower mean weight and height (or length) were more likely to have ARI than the control group and this agrees with studies in which malnutrition and underweight were risks for acute LRTI in children $<5$ years old $[7,18,19]$. However, weight-for-age and height-for-age were not statistically significantly related to ARI. ARI was more likely in underweight children assessed according to the Gomez and Welcome criteria, with the risk around 2-fold higher compared with the control group $(\mathrm{OR}=1.95 ; 95 \% \mathrm{CI}: 1.15-3.30$ and $\mathrm{OR}=2.30$; $95 \% \mathrm{CI}: 1.49-3.58 \mathrm{re}-$ spectively). Wahed and Islam showed that most children with pneumonia had mild protein-energy malnutrition according to Gomez criteria [11]; in our study, $57.9 \%$ were normal and $27.4 \%$ had mild protein-energy malnutrition according to Gomez classes. Malnutrition by Gomez criteria was shown to be more frequent among children with ARI than other diseases, and more frequent in children aged $<5$ years with LRTI rather than URTI [20]. Tupasi et al. found that malnourishment was significantly associated with increased risk of ARI morbidity [13], while a study in a Bombay hospital reveal that the severity of undernutrition correlated with severity of ARI, with $23.9 \%, 21.6 \%$ and $4.5 \%$ of ARI cases having grade I, II, III malnutrition respectively according to Gomez criteria [12]. We found no significant relation between ARI and underweight according to Waterlow criteria.

\section{Conclusion}

Most cases of ARI in this hospital in Erbil occurred below the age of 1 year and boys were more prone to ARI than girls. Malnutrition according to Gomez and Welcome criteria significantly increase the risk of having ARI among children < 5 years of age.

\section{References}

1. Osinusi K, Oyejide O. Child care practice with respect to acute respiratory tract infection in a poor urban community in Nigeria. Reviews of Infectious Diseases, 1990, 12(Suppl. 8):S1039-S1041.

2. Smyth A. Acute respiratory infection. In: Southall D, et al, eds. International Child health care (a practical manual for hospitals worldwide). London, BMJ Publications, 2002:155.

3. Hadi A. Management of acute respiratory infections by community health volunteers : experience of Bangladesh Rural Advancement Committee (BRAC).. Bulletin of the World Health Organization, 2003, 81:183-189.

4. YousifT, Khaleq B. Epidemiology of ARI among children under five years old attending Tikrit General teaching Hospital. Middle East Journal of Family Medicine, 2006, 14(3).

5. Kramer M, Kakuma R. The optimal duration of exclusive breastfeeding: a systemic review. Geneva, World Health Organization, 2002.

6. Classification of malnutrition in children. Medical Criteria [online factsheet] (http://www.medicalcriteria.com/site/index. php?option=com_content\&view=article\&id=275\%3Amalnutr ition \&catid $=66 \% 3$ Anutrition\&ltemid $=80 \&$ lang $=$ en, accessed 20 November 2012)

7. The situation of children in Northern Iraq. An assessment based on the United Nations Convention on the Rights of the Child. Baghdad, Iraq, United Nations Children's Fund, 2002 (http:// old.krg.org/986/unicef-children-sep-2002.pdf, accessed 4 November 2012).

8. Hemalatha R et al. Respiratory syncytial virus in children with acute respiratory infections. Indian Journal of Pediatrics, 2010, 77 (7): 755-758

9. Gupte S. Growth and development. In: Gupte R, ed. In: Short textbook of Pediatrics, 5th ed. New Delhi, Jaypee Brothers, 1985:20-21.
10. Waterlow JC. Classification and definition of protein-calorie malnutrition. British Medical Journal, 1972, 3:566-569.

11. Wahed $\mathrm{M}$ et al. Effect of micronutrients on morbidity and duration of hospital stay in childhood pneumonia. Mymensingh Medical Journal, 2008, 29:519-523.

12. Kanchi P, Kakeri M. ARI and some associated epidemiological factors in children of 0-5 years of age group. Bombay Hospital Journal, 2005, 47.

13. Tupasi $\mathrm{T}$ et al. patterns of acute respiratory tract infection in children: a longitudinal study in a depressed community in Metro Manila. Reviews of Infectious Diseases, 1990, 12 (Suppl. 8):S940-S949.

14. Grant $\mathrm{C}$ et al. Child nutrition and lower respiratory tract burden in New Zealand: A global context for a national perspective. Journal of Pediatrics and Child Health, 2011, 4 (8):497-504.

15. Cunha A. Relationship between acute respiratory tract infection and malnutrition in children under 5 years of age. Acta Paediatrica, 2000, 89(5):608-609.

16. Albargish $\mathrm{K}$, Hasony $\mathrm{H}$. Respiratory syncytial virus infection among children with acute respiratory tract infection in Iraq. Eastern Mediterranean Health Journal, 1999, 5(5):941-948.

17. Al-Jassar NFJ. Clinico-epidemiological study of acute respiratory infections (ARI) in children under 5 years of age. Iraqi Journal of Medical Science, 1994, 10:200-207.

18. Diallo FB et al. The effects of exclusive versus non-exclusive breastfeeding on specific infant morbidities in Conakry. Pan African Medical Journal, 2009, 2:2.

19. Arifeen $\mathrm{S}$ et al. Exclusive breast feeding reduces acute respiratory infection and diarrhea deaths among infants in Dahka slums. Pediatrics, 2001, 108(4):E67.

20. Arnaut I et al. Acute respiratory infections in rural morocco. Arab Journal of Medicine, 1985; 4(10):16-18. 